Research Article

\title{
Rockburst Prediction on the Superimposed Effect of Excavation Accumulation Energy and Blasting Vibration Energy in Deep Roadway
}

\author{
Qingwen Li $(\mathbb{D})$ and Ben Xiang \\ Beijing Key Laboratory of Urban Underground Space Engineering, University of Science and Technology Beijing, \\ Beijing 100083, China \\ Correspondence should be addressed to Qingwen Li; qingwenli@ustb.edu.cn
}

Received 2 November 2020; Revised 7 February 2021; Accepted 27 April 2021; Published 7 May 2021

Academic Editor: Nan Jiang

Copyright ( $) 2021$ Qingwen Li and Ben Xiang. This is an open access article distributed under the Creative Commons Attribution License, which permits unrestricted use, distribution, and reproduction in any medium, provided the original work is properly cited.

In deep mining, much elastic energy is stored in rock mass due to the high geostress. Rockburst will be induced by accumulated energy during excavation. Meanwhile, because of blasting vibration energy in the host rock, there will be an obvious superimposed effect on the probability and intensity of rockburst. To explore the most reasonable and effective method for understanding rockburst problem under blasting, a deep roadway of Sanshandao gold mine was studied. On the basis of in situ geostress data, the accumulated energy of three-centered arch roadway after quasi-static excavation was derived. Then, a series of in situ blasting vibration were monitored, and the blasting vibration energy was calculated by employing the equivalent theory of elastic vibration boundary. Finally, the tendentiousness of rockburst was evaluated qualitatively with the superimposed energy. The results indicated that the disaster-driven energy was increased by $45.1 \%$ and $28.2 \%$ on different places of roadway. Also, the probability and intensity of rockburst would be raised.

\section{Introduction}

Nowadays, resource exploration has entered deep mining. Much elastic energy is stored in rock mass, and deeper buried depth leads to more energy. Many scholars have paid attention to energy storage characteristics of rocks [1-4]. Affected by excavation, the stress and strain will redistribute, resulting in rock damage and destruction. Kong et al. gave a new method to estimate the pressure arch formation above underground excavation in rock mass [5]. Also, the distribution characteristics of stored energy will change. Some energy will release to damage the host rock. Gao et al. studied the rock damage based on the energy principles [6]. Xiao et al. raised a new method for calculating energy release rate in tunnel excavation subjected to high in situ stress [7]. Sometimes, the intense energy releasing process will cause dynamic disasters, especially rockburst. Recently, energy theory has been regarded as the most effective approach to explain the mechanism of deep dynamic disasters and has attracted attentions of scholars around the world. Chen et al. studied the rock burst intensity classification based on the radiated energy with damage intensity at Jinping II Hydropower Station, China [8]. Xu et al. established a new energy index for evaluating the tendency of rockburst and its engineering application also in Jinping II hydropower station [9]. Wang et al. did the research on the energy criterion for rockbursts induced by broken hard and thick rock strata [10]. Miao et al. predicted the rockburst based on in situ stress and energy accumulation theory [11].

Meanwhile, drill and blast is still the main excavation way for the rock mass tunneling [12-14]. Under the action of blasting wave, there are many negative effects, such as host rock damage [15-17], high initial stress release [18], intense stress and strain $[19,20]$, and blasting vibration of surrounding rock mass $[21,22]$, to name a few. Also, due to blasting effect, the energy accumulation degree is much 
higher [23], so the possibility and intensity of rockburst and other dynamic disasters will increase accordingly. Also, some scholars have noticed the relationship between rockburst intensity and rock blasting. Fan et al. studied the influence of tunneling methods on the strainburst characteristics during the excavation of deep rock mass [24]. Liu et al. put forward a method for dynamic risk assessment and management of rockbursts in drill and blast tunnels [25]. However, these methods mentioned above are mainly based on theoretical derivations or numerical simulations. The superposition effect and degree cannot be quantitatively given. Hence, based on the in situ geostress data and energy calculation method of circular tunnels, the accumulated energy of three-centered arch roadway in Sanshandao gold mine after quasi-static excavation was derived. Then, a series of modified SHPB dynamic tests were conducted after employing the equivalent theory of elastic vibration boundary and the monitoring data of near field blasting impact velocity. So, the energy attenuation in the long granite specimens $(400 \mathrm{~mm}$ in length and $50 \mathrm{~mm}$ in diameter) and blasting vibration energy dispersion with different incident bars were confirmed. Finally, according to the superimposed energy, the tendentiousness of rockburst was evaluated qualitatively. So, the effect of blasting vibration on rockburst intensity was quantified, which provides theoretical guidance and supporting data for dynamic disasters of deep rock under blasting vibration conditions.

\section{Energy Accumulation Casused by Deep Roadway Excavation}

2.1. Engineering Cases and Geostress Measurement. The largest exploitation depth in Sanshandao gold mine has already exceeded $1400 \mathrm{~m}$. Rockburst and other dynamic disasters are becoming more and more serious. To study the rockburst tendency, a $1000 \mathrm{~m}$ depth roadway was selected as the research cases. The cross-section diagram of excavated roadway is displayed in Figure 1. The dimensions of the roadway are $4.2 \mathrm{~m}$ in height and $4.5 \mathrm{~m}$ in width. As shown, region I is the roof and the circular arc area of side wall, with the arc radius $2.25 \mathrm{~m}$; region $\mathrm{II}$ is the transition region of side wall and the floor, with the arc radius $0.94 \mathrm{~m}$; and region III is the circular arc area of floor, with the arc radius $4.6 \mathrm{~m}$.

A large number of studies have shown that deep high geostress is the essential cause of dynamic disasters; to obtain accurate geostress measurement data, the stress relief method was employed to measure the in situ geostress, and the adopted in situ stress probe is shown in Figure 2.

In order to acquire the accurate distribution law of geostress, in situ geostress measurements of 11 groups were carried out. After measuring, it is found that all curves show similar stress characteristics. As relief length increases, the measured strain values increase constantly and finally become stable. Typical measuring data curves of geostress are shown in Figure 3. In the legend of Figure 3, A, B, and C are the three sets of strain rosette and $0,45,90$, and 135 are the direction of strain gage in a strain rosette.

The stress relief method is to reverse the stress value according to the measured value of strain recovery value with the basis of generalized Hooke's law, so the elastic modulus and Poisson's ratio of rock cores are necessary for data processing; they can be acquired by the confining pressure rating test (shown in Figure 4(a)), and the following formulas are obtained:

$$
\begin{aligned}
& E=\frac{P_{c}}{\varepsilon_{\theta}} \cdot \frac{2 L^{2}}{L^{2}-l^{2}}, \\
& \nu=\frac{\varepsilon_{z}}{\varepsilon_{\theta}},
\end{aligned}
$$

where $E$ is the elastic modulus; $v$ is the Poisson ratio; $P_{c}$ is the confining pressure; $\varepsilon_{\theta}$ and $\varepsilon_{z}$ are radial and axial strain, respectively; and $L$ and $l$ are outer and inner diameter of the rock core, respectively.

Considering the influence of colloid, formula (1) can be modified as follows:

$$
E=K_{1} \cdot \frac{P_{0}}{\varepsilon_{\theta}} \cdot \frac{2 L^{2}}{L^{2}-l^{2}},
$$

where $K_{1}$ is the compensation factor. When $E \geq 50 \mathrm{MPa}, K_{1}$ is 1.12 .

After in situ strain monitoring, confining pressure calibration tests were carried out on the drilled cores; typical confining pressure rating curves are displayed in Figure 4(b). After analyzing the measured data of 11 points, the value and direction of geostress of Sanshandao gold mine are listed in Table 1, and the fitted results are illustrated in Figure 5.

As listed in Table 1, for the geostresses in three directions, the dip angles of maximum principal stress $\left(\sigma_{1}\right)$ are between $-10^{\circ}$ and $4^{\circ}$; this principal stress is close to the horizontal direction; it is named as the maximum horizontal principal stress $\left(\sigma_{H}\right)$. For the intermediate principal stress $\left(\sigma_{2}\right)$ and minimum principal stress $\left(\sigma_{3}\right)$, one of them is in the near horizontal state and the other one is in the near vertical state by the dip angle analysis. The geostress with near horizontal state is named as the minimum horizontal principal stress $\left(\sigma_{h}\right)$, and the geostress with vertical dip angle is the vertical principal stress $\left(\sigma_{v}\right)$. These three principal stresses all increase linearly with depth, and the maximum horizontal principal stress increases much more rapidly. The relationships between three different principal stress and depth are as follows:

$$
\left\{\begin{array}{l}
\sigma_{H}=0.035 H+7.434, \\
\sigma_{h}=0.017 H+8.366, \\
\sigma_{v}=0.026 H+1.072,
\end{array}\right.
$$

where $H$ is the depth.

Based on the fitting formula (4), taking example of $1000 \mathrm{~m}$ depth geostress, the value of in situ stress values in three directions is as follows: $\sigma_{H}=42.4 \mathrm{MPa}, \sigma_{h}=25.4 \mathrm{MPa}$, and $\sigma_{v}=27.1 \mathrm{MPa}$, and the three values are $35.4,22.0$, and 21.9 for $800 \mathrm{~m}$ depth, respectively. So, for the value of geostress, the minimum horizontal principal stress is almost equal to the vertical principal stress, and the maximum horizontal stress is about 1.6 times the minimum horizontal principal stress and vertical principal stress. 


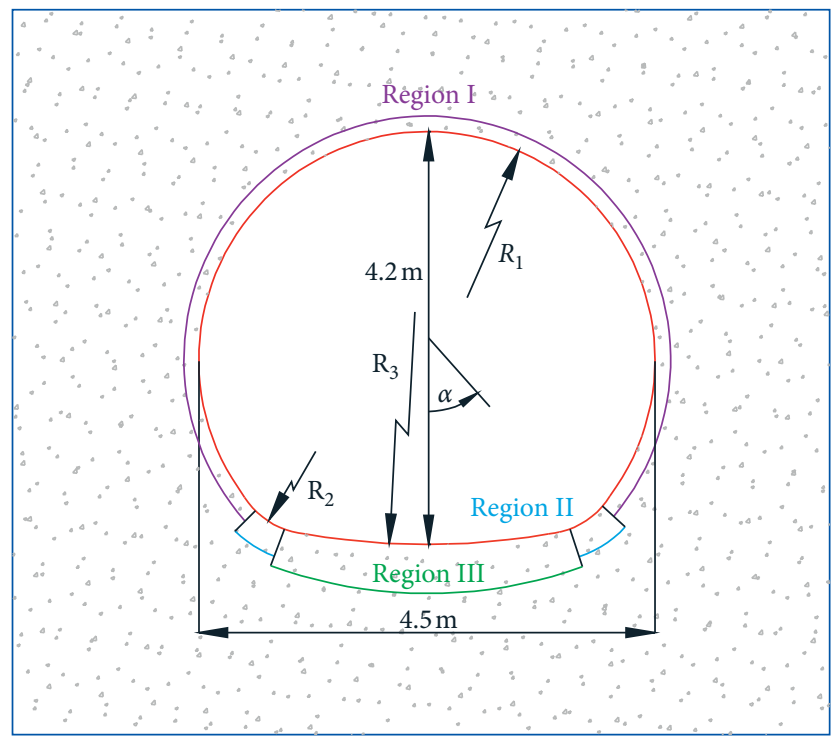

FiguRE 1: The cross-section diagram of excavated roadway and its partition.

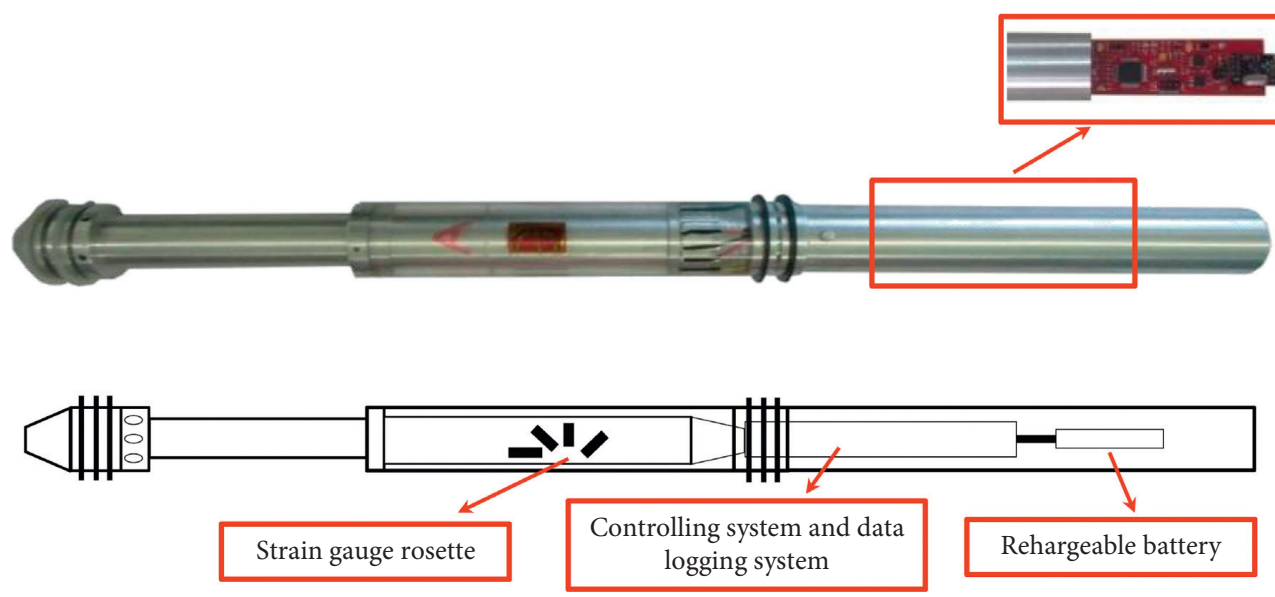

FIgURE 2: The used digital hollow inclusion strain gauge.

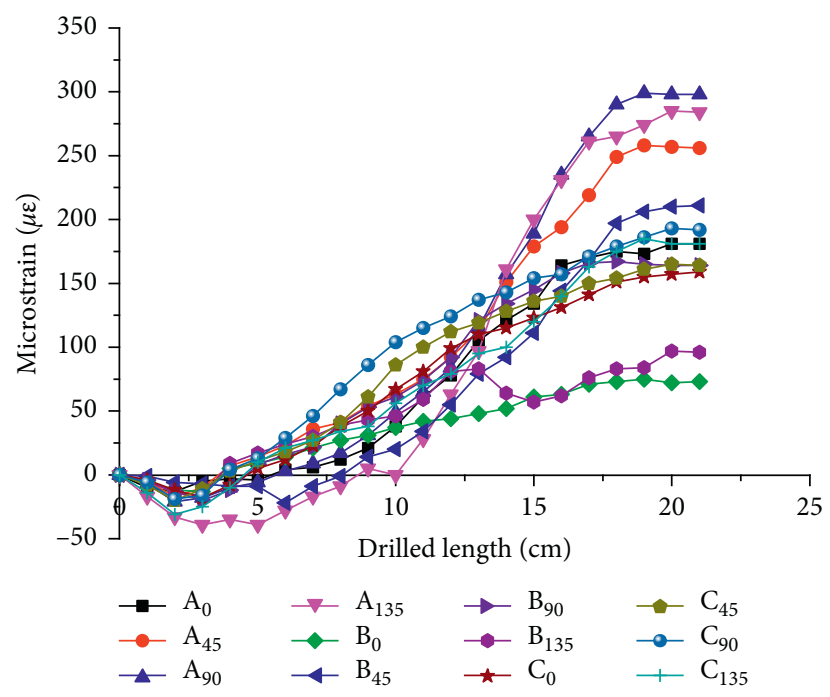

FIgURE 3: Typical measuring data curves of geostress. 


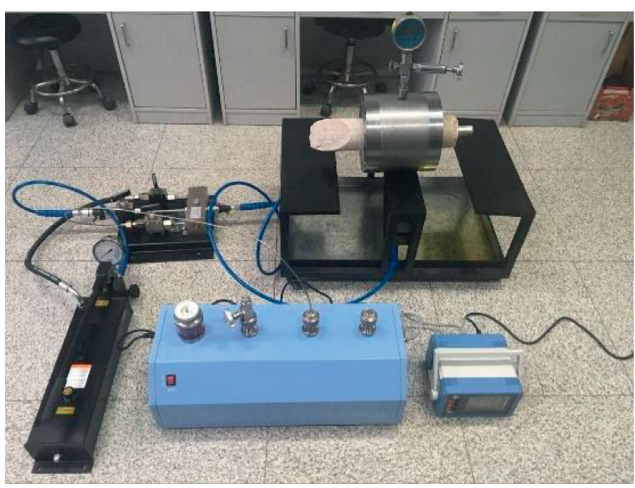

(a)

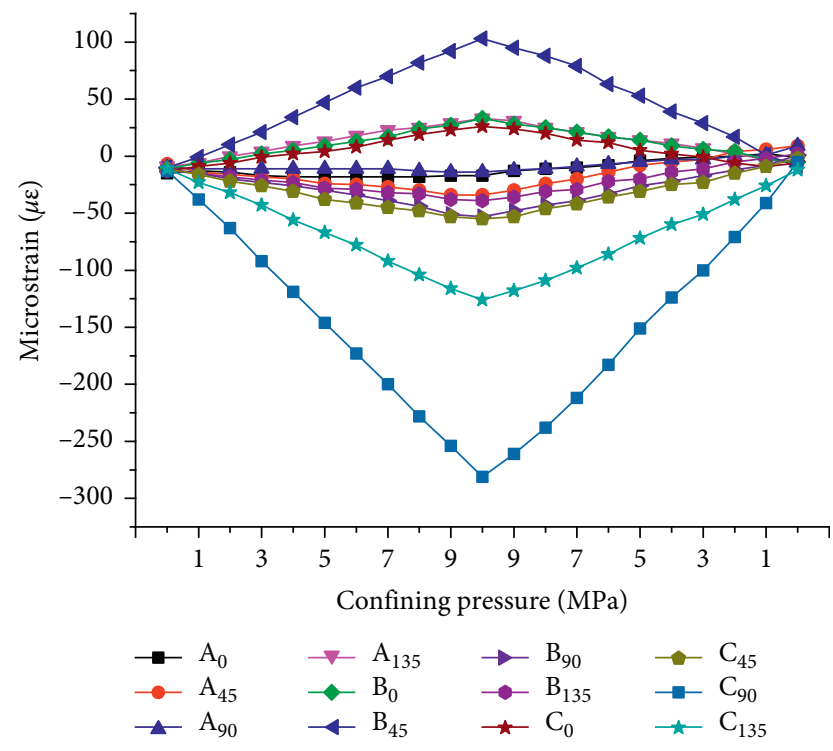

(b)

Figure 4: Confining pressure calibration test and its typical testing curves.

2.2. Analysis of Energy Accumulation in Excavation. To avoid the effect of tectonic stress, most of the underground mine main roadway will be designed and excavated along with the direction of the maximum horizontal stress. So, the maximum horizontal principal stress will be released during excavation. When the roadway is excavated along the maximum horizontal principal stress, the vertical principal stress is very close to the minimum horizontal principal stress based on the geostress monitoring results. So, the excavated roadway can be equivalent to an infinite threecentered arch roadway, and the far field geostress effect can be approximate to hydrostatic pressure, which means $P_{0}=\sigma_{v} \approx \sigma_{h}$. Using the plane strain problem method, the confining pressure of circular roadway can be expressed as follows [26]:

$$
\left\{\begin{array}{l}
\sigma_{1}=P_{0}\left(1+\frac{R^{2}}{r^{2}}\right), \\
\sigma_{2}=P_{0}, \\
\sigma_{3}=P_{0}\left(1-\frac{R^{2}}{r^{2}}\right),
\end{array}\right.
$$

where $\sigma_{1}, \sigma_{2}$, and $\sigma_{3}$ are the first, second, and third principal stress, respectively; $R$ is the radius of roadway; and $r$ is the distance between the surrounding rock to the roadway center.

Then, the strain energy density of surrounding rock is

$$
U=\frac{\left[\sigma_{1}^{2}+\sigma_{2}^{2}+\sigma_{3}^{2}-2 \nu\left(\sigma_{1} \sigma_{2}+\sigma_{2} \sigma_{3}+\sigma_{1} \sigma_{3}\right)\right]}{2 E} .
$$

Under hydrostatic pressure conditions, the stresses in the far field have the rule as

$$
\sigma_{1}=\sigma_{2}=\sigma_{3}=P_{0}
$$

Substituting equations (5) and (7) into equation (6), the strain energy density of surrounding rock before and after excavation can be calculated as follows:

$$
\begin{aligned}
U_{w} & =P_{0}^{2} \frac{\left[3(1-2 \nu)+2(1+\nu)\left(R^{4} / r^{4}\right)\right]}{2 E}, \\
U_{0} & =\frac{P_{0}^{2}[3(1-2 \nu)]}{2 E},
\end{aligned}
$$

where $U_{0}$ and $U_{w}$ are the strain energy density of surrounding rock before and after excavation, respectively.

For any point $N(r, \theta)$ in the three-centered arch roadway, according to the region partition in Figure 4 , when $\theta \in(-\alpha, \alpha)$, which means $N(r, \theta)$ is in the region I, the strain energy density of surrounding rock after excavation is

$$
U_{w 1}=\frac{P_{0}^{2}\left[3(1-2 \nu)+2(1+\nu)\left(R^{4} / r^{4}\right)\right]}{2 E} .
$$

When $N(r, \theta)$ is in the region II, 
TABLe 1: Geostress data from in situ monitoring.

\begin{tabular}{|c|c|c|c|c|c|c|c|c|c|c|}
\hline \multirow[b]{2}{*}{ No. } & \multirow{2}{*}{$\begin{array}{l}\text { Depth } \\
(\mathrm{m})\end{array}$} & \multicolumn{3}{|c|}{ Maximum principal stress $\sigma_{1}$} & \multicolumn{3}{|c|}{ Intermediate principal stress $\sigma_{2}$} & \multicolumn{3}{|c|}{ Minimum principal stress $\sigma_{3}$} \\
\hline & & $\begin{array}{l}\text { Value } \\
(\mathrm{MPa})\end{array}$ & $\begin{array}{c}\text { Direction } \\
\left({ }^{\circ}\right)\end{array}$ & $\begin{array}{c}\text { Dip angle } \\
\left({ }^{\circ}\right)\end{array}$ & $\begin{array}{l}\text { Value } \\
(\mathrm{MPa})\end{array}$ & $\begin{array}{c}\text { Direction } \\
\left({ }^{\circ}\right)\end{array}$ & $\begin{array}{c}\text { Dip angle } \\
\left({ }^{\circ}\right)\end{array}$ & $\begin{array}{l}\text { Value } \\
(\mathrm{MPa})\end{array}$ & $\begin{array}{c}\text { Direction } \\
\left({ }^{\circ}\right)\end{array}$ & $\begin{array}{c}\text { Dip angle } \\
\left({ }^{\circ}\right)\end{array}$ \\
\hline 1 & 510 & 24.55 & 129 & 4 & 16.35 & -138 & 2 & 14.49 & 133 & -85 \\
\hline 2 & 510 & 24.64 & -111 & 3 & 15.68 & 155 & 82 & 15.02 & 161 & -10 \\
\hline 3 & 555 & 25.71 & -45 & -13 & 14.00 & 14 & 73 & 13.00 & 50 & -20 \\
\hline 4 & 645 & 29.57 & 112 & -3 & 19.56 & -177 & -80 & 15.48 & -156 & -9 \\
\hline 5 & 600 & 28.88 & 103 & 1 & 16.54 & 10 & 76 & 14.77 & 13 & -8 \\
\hline 6 & 600 & 30.17 & 110 & -6 & 18.83 & 24 & -11 & 16.94 & 236 & -70 \\
\hline 7 & 690 & 31.50 & -80 & 2 & 19.08 & 230 & -79 & 17.54 & 10 & -10 \\
\hline 8 & 690 & 29.77 & -83 & 4 & 20.84 & -8 & -74 & 19.63 & 8 & 15 \\
\hline 9 & 750 & 33.22 & 119 & -10 & 19.93 & -89 & -82 & 17.10 & 208 & -8 \\
\hline 10 & 795 & 48.93 & 164.09 & 3 & 23.15 & 74.41 & -5.97 & 21.66 & 47.22 & 83.29 \\
\hline 11 & 825 & 46.95 & 40.06 & 3.84 & 28.88 & -49.55 & -5.77 & 26.49 & -83.43 & 83.06 \\
\hline
\end{tabular}

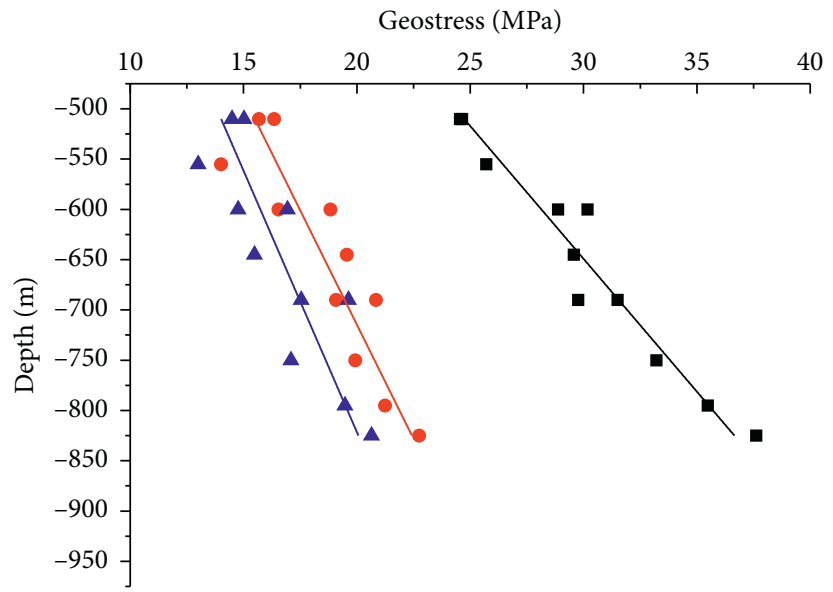

- Maximum horizontal principal stress

- Vertical stress

- Minimum horizontal principal stress

FIgURE 5: The relationship between geostress and depth.

$$
\begin{aligned}
& r^{\prime 2}=\left(R_{1}-R_{2}\right)^{2}+r^{2}-2 r\left(R_{1}-R_{2}\right) \cos \left(\theta-\alpha_{2}\right), \\
& U_{w 2}=\frac{P_{0}^{2}\left[3(1-2 \nu)+2(1+\nu)\left(R_{2}^{4} / r^{\prime 4}\right)\right]}{2 E}=\frac{P_{0}^{2}}{2 E} \frac{3(1-2 \nu)+2(1+\nu) R_{3}^{4}}{\left[\left(R_{1}-R_{2}\right)^{2}+r^{2}-2 r\left(R_{1}-R_{2}\right) \cos \left(\theta-\alpha_{2}\right)\right]^{2}} .
\end{aligned}
$$

When $N(r, \theta)$ is in the region III,

$$
\begin{aligned}
O_{1} O_{2}^{2} & =\left(R_{3}-R_{2}\right)^{2}+\left(R_{1}-R_{2}\right)^{2}-2\left(R_{3}-R_{2}\right)\left(R_{1}-R_{2}\right) \cos \alpha_{3}, \\
r^{\prime \prime 2} & =O_{1} O_{2}^{2}+r^{2}-2 r\left|O_{1} O_{2}\right| \cos \theta, \\
U_{w 3} & =\frac{P_{0}^{2}}{2 E_{0}} \frac{[3(1-2 \nu)+2(1+v)] R_{3}^{4}}{O_{1} O_{2}^{2}+r^{2}-2 r\left|O_{1} O_{2}\right| \cos \theta} .
\end{aligned}
$$


Substituting in situ geostress data, elastic modulus, and Poisson's ratio into formulas (9)-(14), the quasi static energy distribution of host rock mass can be fitted, as shown in Figure 6.

It can be seen from Figure 6 that after excavation, the maximum accumulated energy on the top and both sides of the roadway is $89.7 \mathrm{~kJ} / \mathrm{m}^{3}$. For the bottom of the roadway, the value is $143.6 \mathrm{~kJ} / \mathrm{m}^{3}$. The maximum values all appear in the host rock at the location $5 \mathrm{~m}$ from the free face.

\section{Energy Superposition Effect by Blasting Vibration}

3.1. Confirmation of Equivalent Elastic Vibration Zone. Blasting in the rock mass is a very complicated process; the energy produced by the explosion of an explosive can be roughly divided into two parts: one is for the excavation of the target rock mass and the other can produce the rock mass vibration at a certain distance. Under these combination effects, different damage zones are formed. Based on the damage types and degrees, the recognized zones are blasting crushed zone, blasting fragmentation zone, and elastic vibration zone, as shown in Figure 7 ,

As seen in Figure 7, some of the energy of the explosion will be consumed in blasting crushed zone and blasting fragmentation zone to excavate target rock mass. The remaining energy will propagate outward in the form of a vibrational wave; this part energy will have a superimposed effect on the accumulated energy of rock mass. Therefore, for the analysis of energy superposition effect by blasting vibration, an equivalent elastic vibration boundary (region 4 in Figure 7 ) could be adopted. In this region, the blasting wave can be recognized as the elastic wave gradually decays along the radius [27]. When single-hole blasting is used for infinite rock, the failure mode of rocks in blasting crushed zone is mainly shearing failure. While for the rocks in blasting fragmentation zone, it is tensile failure. The radius can be calculated by the following equation [28]:

$$
\begin{aligned}
& r_{1}=\left(\frac{\rho_{r} c_{p}^{2}}{5 \sigma_{c}}\right)^{1 / 2}\left(\frac{P}{\sigma_{*}}\right)^{1 / 4} r_{0}, \\
& r_{2}=\left[\frac{v P}{(1-v) \sigma_{t}}\right]^{1 / \alpha} r_{0}
\end{aligned}
$$

where $r_{0}$ is the radius of blasting drill hole; $r_{1}$ is the radius of blasting crushed zone; $r_{2}$ is the radius of blasting fragmentation zone; $c_{p}$ is the velocity of $P$ wave in the rock; $\sigma_{c}$ is the dynamic compressive strength; $\sigma_{t}$ is the dynamic tensile strength; $\sigma_{*}$ is the static compressive strength; $P$ is the blasting loading; $\alpha$ is the attenuation coefficient of vibration wave; and $\rho_{r}$ is the density of rock.

Here, $c_{p}^{2}=\lambda+2 G / \rho_{r}, \lambda=2 G v / 1-2 v$, and $G$ is the shear modulus.
Calculations suggest that the radius of single-hole blasting crushed zone is 4 times the radius of blasting hole. For the blasting fragmentation zone, the value is ten times. Therefore, in this paper, 10 times of blasting hole radius can be equivalent to elastic vibration zone [29].

3.2. In Situ Blasting Vibration Wave Monitoring. For the in situ blasting, the drilled blasting hole is $40 \mathrm{~mm}$; according to the equivalent elastic vibration zone model, the range of blasting crush zone in the rock mass is $160 \mathrm{~mm}$ around blasting hole and the range of blasting fragmentation zone is about $400 \mathrm{~mm}$ around blasting hole. It also means that the blasting energy will propagate outward in the form of vibration waves out of the range of $0.4 \mathrm{~m}$. To acquire accurate velocity of blasting vibration wave, Ubox-5016 blasting vibration monitor (see Figure 8) was used in in situ blasting monitoring.

Because it is close to the roadway working face, it is difficult to conduct in situ monitoring. Here, 7 groups of near-field blasting vibration monitoring were applied, and the monitoring location and monitoring results are shown in Table 2.

After data analysis, the attenuation law of vibration velocity with blasting distance could be fitted as shown in Figure 9.

As shown in Figure 9, the peak velocity of blasting decreases gradually with the increase of the propagation distance in rock mass, and the total vibration velocity will attenuate by the formula in Figure 9.

\section{Rockburst Tendentiousness Analysis}

According to the value of elastic energy, the rockburst intensity can be divided into four degrees, as shown in Table 3.

As calculated in Section 2.2, without considering the explosion vibration effect, the maximum accumulated energy on the top and both sides of the roadway is $89.7 \mathrm{~kJ} / \mathrm{m}^{3}$ after excavation. For the bottom of the roadway, the value is $143.6 \mathrm{~kJ} / \mathrm{m}^{3}$. These two values indicate that the rockburst intensity is slight and medium, respectively. The maximum values all appear at about $5 \mathrm{~m}$ from the free face.

At $5 \mathrm{~m}$ position in the host rock, the velocity caused by blasting is $3.86 \mathrm{~m} / \mathrm{s}$ which is calculated by the formula in Figure 9. Taking the theorem of kinetic energy, the energy density per unit volume of rock mass could be calculated by considering the granite density $2712 \mathrm{~kg} / \mathrm{m}^{3}$, and the blasting vibration energy density is $40.41 \mathrm{~kJ} / \mathrm{m}^{3}$. Then, the accumulated energy has risen to $130.11 \mathrm{~kJ} / \mathrm{m}^{3}$ on the top and both sides of the roadway and $184.01 \mathrm{~kJ} / \mathrm{m}^{3}$ on the bottom of the roadway. The accumulated energy increase rates are $45.1 \%$ and $28.2 \%$, respectively, and the rockburst intensity has risen to medium. It can be seen that blasting vibration obviously increases the probability and intensity of the rockburst, which increases the potential threat of dynamic disasters at a certain extent. 


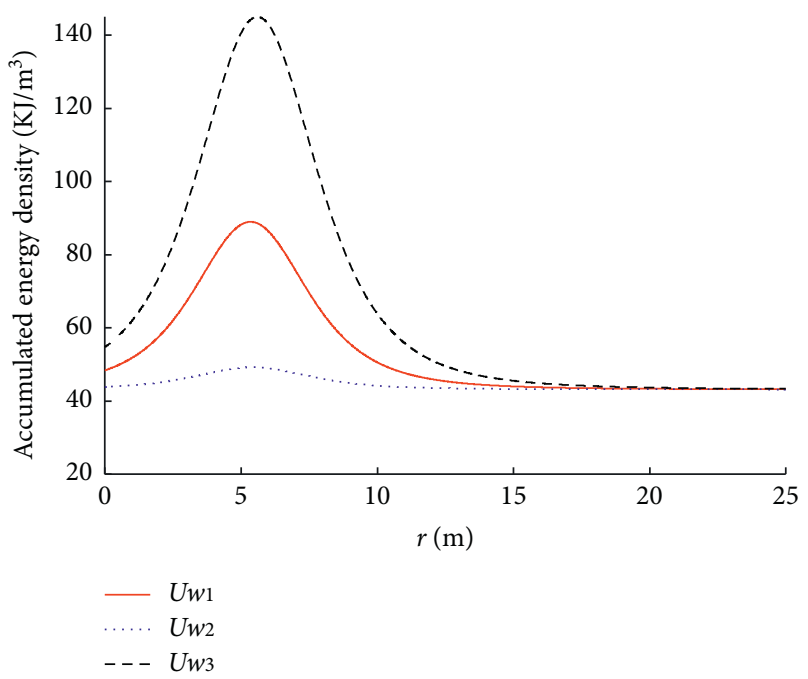

Figure 6: The quasi static energy distribution of surrounding rock mass.

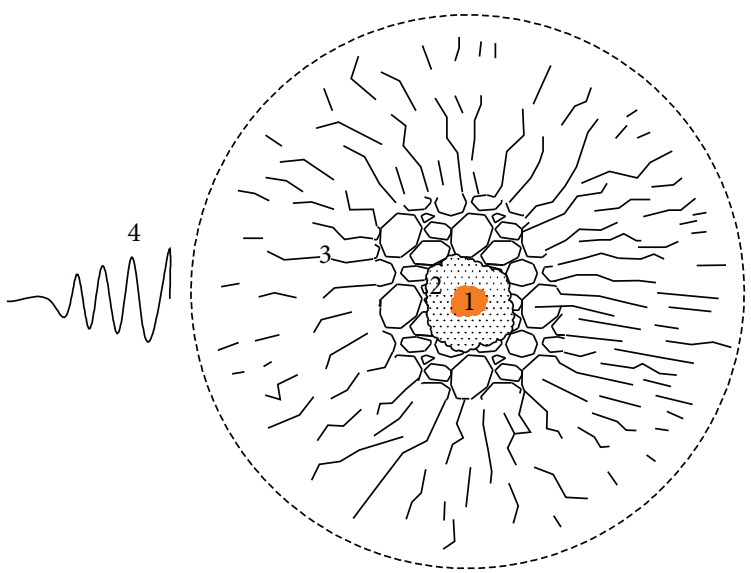

1: blasting hole

2: blasting crushed zone

3: blasting fragmentation zone

4: elastic vibration zone

Figure 7: Sketch diagram of drilled hole blasting.

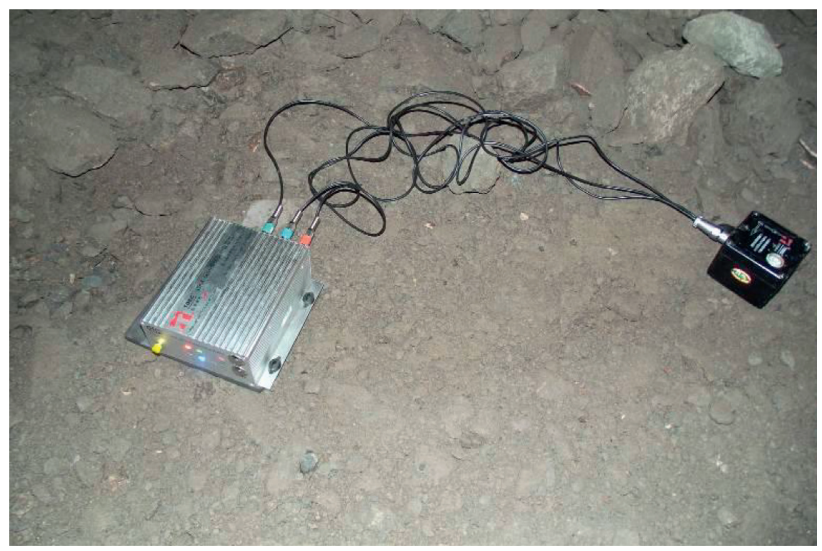

FIGURE 8: Ubox-5016 blasting vibration monitor. 
TABLE 2: Monitoring location and results of near-field blasting vibration.

\begin{tabular}{lcccc}
\hline Blasting distance $(\mathrm{m})$ & $X$-velocity $(\mathrm{m} / \mathrm{s})$ & $Y$-velocity $(\mathrm{m} / \mathrm{s})$ & $Z$-velocity $(\mathrm{m} / \mathrm{s})$ & Velocity $(\mathrm{m} / \mathrm{s})$ \\
\hline 4.2 & 1.82 & 1.23 & 1.91 & 1.79 \\
3.6 & 2.12 & 2.04 & 3.51 & 3.44 \\
2.4 & 3.52 & 3.36 & 1.83 & 6.00 \\
4.4 & 2.01 & 1.95 & 2.23 & 3.49 \\
3.8 & 2.35 & 2.24 & 1.96 & 3.94 \\
3.2 & 2.57 & 2.16 & 2.89 & 5.12 \\
2.6 & 3.18 & 2.79 & & \\
\hline
\end{tabular}

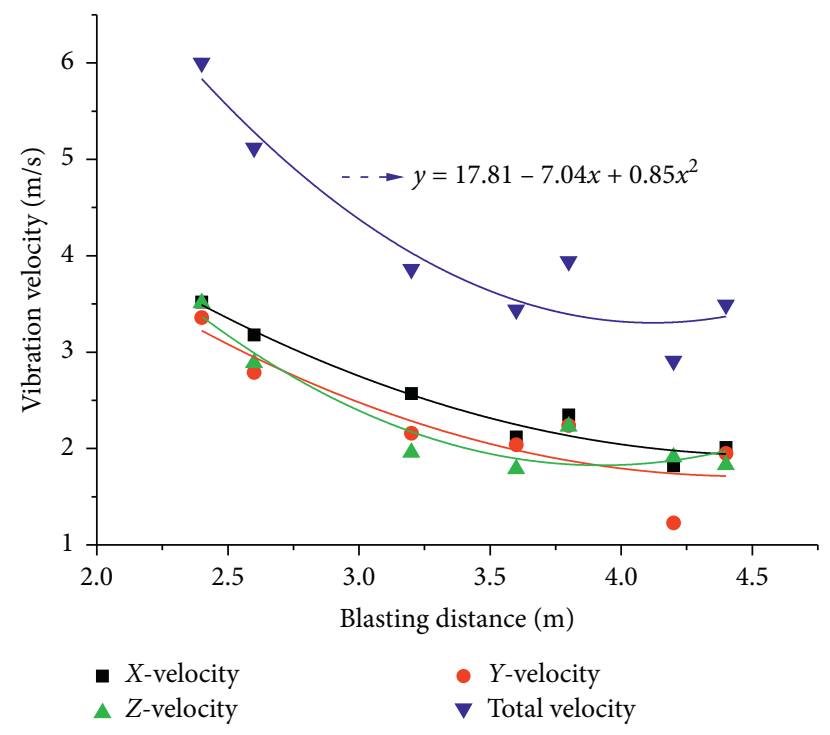

FIgURE 9: Blasting vibration velocity attenuation curve with distance.

TABle 3: Grading value of rockburst tendentiousness.

\begin{tabular}{|c|c|c|c|c|}
\hline Rockburst degree & None & Slight & Medium & Intensity \\
\hline Energy density value $\left(\mathrm{kJ} / \mathrm{m}^{3}\right)$ & $U_{e}<40$ & $40 \leq U_{e}<100$ & $100 \leq U_{e}<200$ & $200<U_{e}$ \\
\hline
\end{tabular}

\section{Conclusions}

Considering the superimposed effect of excavation accumulation energy and blasting vibration energy in deep roadway,

(1) Based on the in situ geostress data and energy calculation method of circular tunnels, the accumulated energy of three-centered arch roadway after quasistatic excavation was derived. The maximum accumulated energy on the top and both sides of the roadway is $89.7 \mathrm{~kJ} / \mathrm{m}^{3}$ after excavation. For the bottom of the roadway, the value is $143.6 \mathrm{~kJ} / \mathrm{m}^{3}$. The maximum values all appear at about $5 \mathrm{~m}$ from the free face.

(2) Based on near-field monitored data, the attenuation law blasting vibration velocity could be fitted, and the result shows that the peak velocity of blasting will decrease gradually with the increase of the propagation distance.

(3) After considering blasting vibration, the accumulated energy has risen to $130.11 \mathrm{~kJ} / \mathrm{m}^{3}$ on the top and both sides of the roadway and $184.01 \mathrm{~kJ} / \mathrm{m}^{3}$ on the bottom of the roadway. There is an increase of $45.1 \%$ and $28.2 \%$, respectively. It can be seen that blasting vibration obviously increases the probability and intensity of the rockburst, which increases the potential threat of dynamic disasters at a certain extent.

\section{Data Availability}

The datasets used in the present study are available from the corresponding author upon reasonable request. 


\section{Conflicts of Interest}

The authors declare that they have no conflicts of interest.

\section{Acknowledgments}

This work was supported by the National Natural Science Foundation of China (U1806209) and the Fundamental Research Funds for the Central Universities (FRF-TP-19021A3 and FRF-IDRY-19-002).

\section{References}

[1] D. Li, Z. Sun, T. Xie, X. Li, and P. G. Ranjith, "Energy evolution characteristics of hard rock during triaxial failure with different loading and unloading paths," Engineering Geology, vol. 228, pp. 270-281, 2017.

[2] M. Soleiman Dehkordi, K. Shahriar, P. Moarefvand, and M. Gharouninik, "Application of the strain energy to estimate the rock load in squeezing ground condition of eamzade hashem tunnel in Iran," Arabian Journal of Geosciences, vol. 6, no. 4, pp. 1241-1248, 2013.

[3] I. C. Engin, F. Bayram, and N. E. Yasitli, "Experimental and statistical evaluation of cutting methods in relation to specific energy and rock properties," Rock Mechanics and Rock Engineering, vol. 46, no. 4, pp. 755-766, 2013.

[4] M. Mirahmadi, M. Tabaei, and M. S. Dehkordi, "Estimation of the specific energy of TBM using the strain energy of rock mass, case study: amir-kabir water transferring tunnel of Iran," Geotechnical and Geological Engineering, vol. 35, no. 5, pp. 1991-2002, 2017.

[5] X. X. Kong, Q. S. Liu, Q. B. Zhang, Y. X. Wu, and J. Zhao, “A method to estimate the pressure arch formation above underground excavation in rock mass," Tunnelling and Underground Space Technology, vol. 71, pp. 382-390, 2018.

[6] W. Gao, L. Wang, and D. Y. Yang, "Rock damage research based on the energy principles," Applied Mechanics and Materials, vol. 87, pp. 238-242, 2011.

[7] Q. H. Xiao, J. G. Liu, S. X. Lei, and B. Gao, "A new method for calculating energyrelease rate in tunnel excavation subjectedto high in situ stress," Perspectives in Science, vol. 7, pp. 292-298, 2016.

[8] B.-R. Chen, X.-T. Feng, Q.-P. Li, R.-Z. Luo, and S. Li, "Rock burst intensity classification based on the radiated energy with damage intensity at jinping II hydropower station, China," Rock Mechanics and Rock Engineering, vol. 48, no. 1, pp. 289-303, 2015.

[9] J. Xu, J. Jiang, N. Xu, Q. Liu, and Y. Gao, “A new energy index for evaluating the tendency of rockburst and its engineering application," Engineering Geology, vol. 230, pp. 46-54, 2017.

[10] J. Wang, J. Ning, J. Jiang, T. Bu, and X. Shi, "Research on the energy criterion for rockbursts induced by broken hard and thick rock strata and its application," Geotechnical and Geological Engineering, vol. 35, no. 2, pp. 731-746, 2017.

[11] S.-J. Miao, M.-F. Cai, Q.-F. Guo, and Z.-J. Huang, "Rock burst prediction based on in-situ stress and energy accumulation theory," International Journal of Rock Mechanics and Mining Sciences, vol. 83, pp. 86-94, 2016.

[12] J. Yang, W. Lu, M. Chen, P. Yan, and C. Zhou, "Microseism induced by transient release of in situ stress during deep rock mass excavation by blasting," Rock Mechanics and Rock Engineering, vol. 46, no. 4, pp. 859-875, 2013.
[13] J. Yang, W. Lu, Y. Hu, M. Chen, and P. Yan, "Numerical simulation of rock mass damage evolution during deepburied tunnel excavation by drill and blast," Rock Mechanics and Rock Engineering, vol. 48, no. 5, pp. 2045-2059, 2015.

[14] J. Yang, W. Lu, Q. Jiang, C. Yao, S. Jiang, and L. Tian, “A study on the vibration frequency of blasting excavation in highly stressed rock masses," Rock Mechanics and Rock Engineering, vol. 49, no. 7, pp. 2825-2843, 2016.

[15] L. X. Xie, W. B. Lu, Q. B. Zhang, Q. H. Jiang, G. H. Wang, and J. Zhao, "Damage evolution mechanisms of rock in deep tunnels induced by cut blasting," Tunnelling and Underground Space Technology, vol. 58, pp. 257-270, 2016.

[16] H. K. Verma, N. K. Samadhiya, M. Singh, R. K. Goel, and P. K. Singh, "Blast induced rock mass damage around tunnels," Tunnelling and Underground Space Technology, vol. 71, pp. 149-158, 2018.

[17] M. Chen, W. B. Lu, P. Yan, and Y. G. Hu, "Blasting excavation induced damage of surrounding rock masses in deep-buried tunnels," KSCE Journal of Civil Engineering, vol. 20, no. 2, pp. 933-942, 2016.

[18] W. Cao, X. Li, M. Tao, and Z. Zhou, "Vibrations induced by high initial stress release during underground excavations," Tunnelling and Underground Space Technology, vol. 53, pp. 78-95, 2016.

[19] J. González-Cao, L. R. Alejano, E. Alonso, and F. G. Bastante, "Convergence-confinement curve analysis of excavation stress and strain resulting from blast-induced damage," Tunnelling and Underground Space Technology, vol. 73, pp. 162-169, 2018.

[20] J. H. Yang, Q. H. Jiang, Q. B. Zhang, and J. Zhao, "Dynamic stress adjustment and rock damage during blasting excavation in a deep-buried circular tunnel," Tunnelling and Underground Space Technology, vol. 71, pp. 591-604, 2018.

[21] J. H. Yang, W. B. Lu, P. Li, and P. Yan, "Evaluation of rock vibration generated in blasting excavation of deep-buried tunnels," KSCE Journal of Civil Engineering, vol. 22, no. 3, pp. 1-16, 2017.

[22] B. Duan, H. Xia, and X. Yang, "Impacts of bench blasting vibration on the stability of the surrounding rock masses of roadways," Tunnelling and Underground Space Technology, vol. 71, pp. 605-622, 2018.

[23] Y. Fan, W. B. Lu, P. Yan, M. Chen, and Y. Z. Zhang, "Transient characters of energy changes induced by blasting excavation of deep-buried tunnels," Tunnelling and Underground Space Technology, vol. 49, pp. 9-17, 2015.

[24] Y. Fan, W. Lu, Y. Zhou, P. Yan, Z. Leng, and M. Chen, "Influence of tunneling methods on the strainburst characteristics during the excavation of deep rock masses," Engineering Geology, vol. 201, pp. 85-95, 2016.

[25] G.-F. Liu, X.-T. Feng, G.-L. Feng, B.-R. Chen, D.-F. Chen, and S.-Q. Duan, "A method for dynamic risk assessment and management of rockbursts in drill and blast tunnels," Rock Mechanics and Rock Engineering, vol. 49, no. 8, pp. 32573279, 2016.

[26] Y. Fan, W. B. Lu, Y. H. Zhou, P. Yan, and M. Chen, "Study on energy release process of high energy storage rock mass induced byexcavation unloading," Chinese Journal of Rock Mechanics and Engineering, vol. 35, no. S2, pp. 3706-3715, 2016, (in Chinese).

[27] W. Lu, J. Yang, M. Chen, and C. Zhou, "An equivalent method for blasting vibration simulation," Simulation Modelling Practice and Theory, vol. 19, no. 9, pp. 2050-2062, 2011.

[28] A. H. Xahykaeb, Physical Process of Rock Blasting in Mining, Mineral Press, Leningrad, Russia, 1974. 
[29] Q. Li, L. Qiao, G. Dasgupta, S. Ma, L. Wang, and J. Dong, "Blasting vibration safety criterion analysis with equivalent elastic boundary: based on accurate loading model," Shock and Vibration, vol. 2015, pp. 1-10, 2015. 